Conclusions: The treatment is effective in the prevention of abortions. Our results demonstrate a decrease in the number of abortions and a larger number of term pregnancies since the inclusion of patients with high risk pregnancies in our unit. The multidisciplinary evaluation is essential to prevent complications in women diagnosed with APS and thrombophilia in order to reduce adverse pregnancy outcomes and exacerbations of the mother's pathology.

Disclosure of Interest: None declared

DOI: 10.1136/annrheumdis-2018-eular.4912

\section{AB0582 SOLUBLE TRIGGERING RECEPTOR EXPRESSED ON MYELOID CELLS-1 (STREM-1) AND ADRENOMEDULIN ARE ELEVATED IN PATIENTS WITH SYSTEMIC LUPUS ERYTHEMATOSUS}

I. Jeremic ${ }^{1}$, N. Stojanovic ${ }^{1}$, Z. Stanojevic ${ }^{2}$, B. Jovanovic ${ }^{3}$, J. Tosic ${ }^{2}$, S. Vidicevic ${ }^{2}$, A. Isakovic ${ }^{2} .{ }^{1}$ Institute of Rheumatology, Belgrade; ${ }^{2}$ Institute of Biochemistry, Belgrade; ${ }^{3}$ Clinical Centre of Serbia, Belgrade, Serbia

Background: Adrenomedulin is a peptide firstly isolated from human phaeochromocytoma with vasodilatory effects. Secretion of adrenomedulin is modified by inflammatory cytokines and it may be important as a suppressor of lupus nephritis activity. Triggering receptor expressed on myeloid cells-1 (TREM) is a member of immunoglobulin superfamily clearly elevated in inflammatory conditions. Some subgroups of patients with systemic lupus erythematosus-SLE may have especially elevated levels of s-TREM.

Objectives: The aim of this study was to examine adrenomedulin and s-TREM levels in patients with SLE and healthy controls and to assess their relation with SLE disease activity index-SLEDAI

Methods: Serum samples from 50 SEL patients and 40 healthy blood donors were analysed. Serum levels of adrenomedulin, s-TREM, complement components $\mathrm{C} 3$ and $\mathrm{C} 3$, and anti-dsDNA antibodies were measured

Results: Patients with SLE had higher adrenomedulin $(9.8 \pm 4.5$ vs. $15.3 \pm 7.2 \mathrm{pg} /$ $\mathrm{mL}, p<0.05)$ and $s$-TREM $(11.7 \pm 4.1$ vs. $20.3 \pm 13.1 \mathrm{pg} / \mathrm{mL})(p<0.05)$ levels. $\mathrm{s}-$ TREM showed correlation with anti-dsDNA antibodies $(\rho=0.405, p<0.05)$ and SLEDAI score $(\rho=0.386, p<0.001)$. In multivariate analysis s-TREM did not appear as an independent predictor of SLEDAI score, while only anti-dsDNA antibodies were significant in multivariate analysis.

Conclusions: Increased adrenomedulin and s-TREM are found in lupus sera. Despite of correlation with SLEDAI score, s-TREM is not better then anti-dsDNA antibodies as a predictor of SLE disease activity.

Disclosure of Interest: None declared

DOI: 10.1136/annrheumdis-2018-eular.6570

\section{AB0583 NEOPLASIA PREVALENCE IN PRIMARY SJÖGREN'S SYNDROME IN HISPANIC PATIENTS}

J.C. Riega-Torres ${ }^{1}$, J. Hermosillo-Villafranca ${ }^{1}$, G. Hernandez-Molina ${ }^{2}$, R. BarbosaCobos $^{3}$, C. Skinner-Taylor ${ }^{1}$, M. Garza-Elizondo ${ }^{1}$, A. Garcia-Garcia ${ }^{1}$, E. FloresHuerta'. '. Servicio de Reumatologia e Inmunologia Clinica, Departamento de Medicina Interna, Hospital Universitario "Jose E. Gonzalez", Monterrey;

${ }^{2}$ Departamento deReumatologia e Inmunologia, Instituto Nacional de Ciencias Médicas y Nutrición "Salvador Zubirán"/; ${ }^{3}$ Servicio de Reumatología, Juárez de México/Centro Médico ABC, Mexico, Mexico

Background: A rheumatic disease may be a casual factor in the pathogenesis of a neoplastic disease, as in other cases, cancer may lead to the development of paraneoplastic rheumatic manifestations that may be the only initial symptoms ${ }^{1}$. Lazarus et al. demonstrated in its cohort study with 112 patients that of the $22 \%$ of patients who developed some neoplasm during the study, the most prevalent was lymphoma with $44 \%$. according to the same study, patients with pss present a risk 37.5 times more than that of the general population. of generating lymphoma, with another risk 2.6 times of developing another type of cancer ${ }^{2}$.it was also shown that in patients with pss there is an incidence of 320 cases per 100000 a year of presenting non-hodgkin's lymphoma ${ }^{3}$. In our country there are no epidemiological studies to know the prevalence of cancer in patients with pss, so these numbers are difficult to estimate

Objectives: Determine the prevalence of cancer in patients with ss in the mexican population

Methods: Cross-sectional, observational study was conducted in which 393 patients were included, of which $221(52 \%)$ came from the national institute of medical sciences and nutrition "salvador zubiran", $92(23.4 \%)$ from the university hospital "José E González" and 80 (20.6\%) of the juárez mexico hospital/ABC medical centre whom fulfilled the diagnosis of ssp according to the 2002/2012 criteria of the american college of rheumatology/european league against rheumatism. Bivariate anailsis was performed, normality was demonstrated using the K.S test, the student's T test was used for the numerical variables and the chi2 test for the categorical ones, and no difference was found between the characteristics of patients with or without cancer.

Results: We include 393 patients, the majority were women ( $n=377,95.9 \%)$ with an average age of $56.4( \pm 13.60)$, of these $23(5.85 \%)$ had some type of neoplasm regardless of their malignancy. the most prevalent was lymphoma with 9 cases (34.6\%), followed by breast cancer with $5(19.2 \%), 3(11.5 \%)$ of basal cell cancer and $2(7.7 \%)$ cases of cervical uterine cancer

Abstract AB0583 - Table 1. Demographic characteristics in Patients with Primary Sjögren Syndrome (n:393)

\begin{tabular}{llll}
\hline & Neoplasia & No neoplasia & $P$ \\
\hline Age years, mean(SD) & $61.57(15.40)$ & $56.10(13.44)$ & 0.519 \\
Female gender, $n(\%)$ & $23(100 \%)$ & $354(95.7 \%)$ & 0.309 \\
Positive Anti-Ro/SSA, n(\%) & $15(71.4 \%)$ & $238(64.7 \%)$ & 0.528 \\
Positive Anti-La/SSB, $n(\%)$ & $9(42.9 \%)$ & $168(46.3 \%)$ & 0.760 \\
Positive Schirmer test, $n(\%)$ & $15(78.9 \%)$ & $245(83.9 \%)$ & 0.572 \\
Abnormal NSWSF,n(\%) & $12(63.2 \%)$ & $215(77.1 \%)$ & 0.169 \\
Positive GSM biopsy, $n(\%)$ & $18(81.8 \%)$ & $276(77.1 \%)$ & 0.607 \\
Use of glucocorticoids, $n(\%)$ & $9(45 \%)$ & $131(36.2 \%)$ & 0.426 \\
Use of hydroxychloroquine, $n(\%)$ & $6(28.6 \%)$ & $167(46.1 \%)$ & 0.116 \\
Use of methotrexate, n(\%) & $3(15 \%)$ & $74(20.4 \%)$ & 0.555 \\
Another immunosuppressive agent, $n$ (\%) & $5(21.7 \%)$ & $76(20.5 \%)$ & 0.890 \\
NSWSF: non-stimulated whole salivary flow, MSG: Minor salivary gland \\
\hline
\end{tabular}

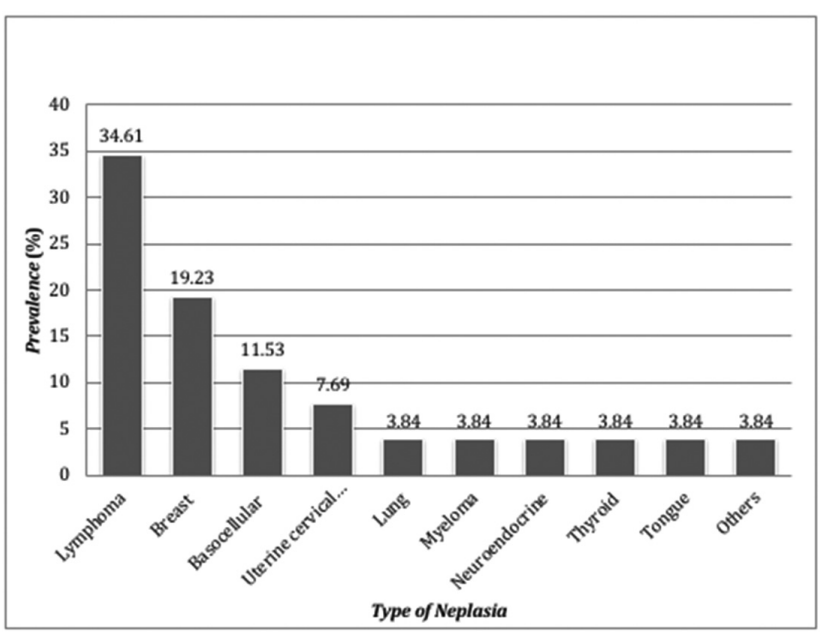

Abstract AB0583 - Figure 1. Neoplasia prevalence in primary sjögren syndrome in Mexican-Mextizo patients

Conclusions: We confirmed lymphoma as the most prevalent neoplasia in a cohort of non-Caucasian pSS patients. We observed the presence of non-hematologicalmalignancy $60.86 \%$ of our patients, whether it risk is increased in pSS population still needs to be addressed.

\section{REFERENCES :}

[1] Bellan M, Boggio E, Sola D, Gibbin A, Gualerzi A, Favretto S, ... Sainagh PP. Association between rheumatic diseases and cancer: results from a clinical practice cohort study. Internal and Emergency Medicine 2017;12 (5):621-627.

[2] Lazarus MN. Incidence of cancer in a cohort of patients with primary Sjogren's syndrome. Rheumatology 2006;45(8):1012-1015

[3] Nishishinya MB, Pereda CA, Muñoz-Fernández S, Pego-Reigosa JM, RúaFigueroa I, Andreu JL, ... Santamaría EL. Identification of lymphoma predictors in patients with primary Sjögren's syndrome: A systematic literature review and meta-analysis. Rheumatology International 2015;35(1):17-26.

Disclosure of Interest: None declared

DOI: 10.1136/annrheumdis-2018-eular.7495 